Revista Eletrônica do Mestrado em Educação Ambiental

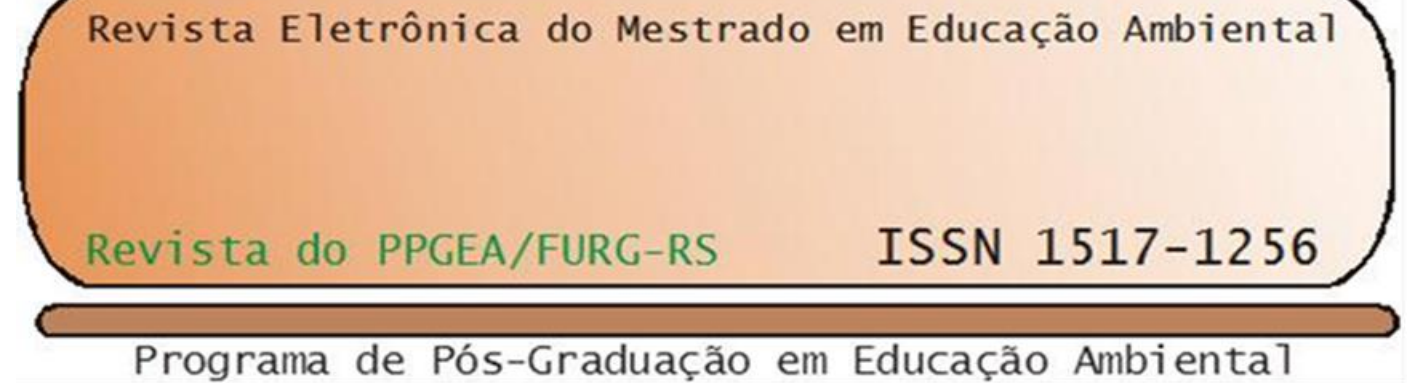

\title{
Paulo Freire vive! 20 anos de sonhos e utopias na práxis político-pedagógica ${ }^{1}$
}

Ivo Dickmann ${ }^{2}$

\author{
Gostaria de ser lembrado como um sujeito \\ que amou profundamente o mundo e as pessoas, \\ os bichos, as árvores, as águas, a vida.
}

(Paulo Freire)

Resumo: Este artigo é parte de uma trilogia que estou produzindo em homenagem a Paulo Freire nos 20 anos de sua morte, para registrar sua presença na práxis dos educadores e fazer memória do seu legado de sonhos e utopias. Apresenta-se aspectos da crise da democracia no Brasil e simula criticamente o discurso de Paulo Freire frente ao golpe jurídico-parlamentar de maio-agosto de 2016, apresentando ainda uma chamada para a luta nas trincheiras em que os educadores se encontram para superar esse cenário de ataque sistemático à educação. Finalizamos com uma demonstração da atualidade do pensamento e práxis freirianas como um caleidoscópio políticopedagógico-histórico-cultural-ético-estético-epistemológico que se constitui como um processo pelo qual nossa palavração contribui na construção de nossa palavramundo, como discípulos de Freire que seguem a sua orientação de não segui-lo, mas reinventá-lo a partir da nossa realidade histórica concreta.

Palavras-chave: Paulo Freire, trilogia, práxis, sonhos, utopia.

\section{Paulo Freire lives! 20 years of dreams and utopias in political-pedagogical praxis}

Abstract: This article is part of a trilogy that I am producing in honor of Paulo Freire in the 20 years of his death, to register his presence in the praxis of educators and to remember his legacy of dreams and utopias. It presents aspects of the crisis of democracy in Brazil and critically simulates the speech of Paulo Freire against the juridic-parlamentary coup of May-August 2016, and also presents a call for the struggle in the trenches in which educators meet to overcome this scenario of systematic attack on education. We conclude with a demonstration of the currentness of Freirean thought and praxis as a political-pedagogical-historical-cultural-ethical-aesthetic-epistemological kaleidoscope that is constituted as a process by which our word-action contributes to the

\footnotetext{
${ }^{1}$ Esse artigo é parte integrante de uma trilogia que estou produzindo em homenagem a Paulo Freire pela passagem dos 20 anos de sua partida entre nós; sendo que uma primeira versão - ou primeira parte, já que os três textos são sempre uma releitura mais ampliada um dos outros -, está publicada na coletânea Pedagogia da Memória (DICKMANN, 2017).

${ }^{2}$ Pós-doutorando em Educação (UNINOVE), Bacharel em Filosofia (IFIBE), Mestre e Doutor em Educação (UFPR). Professor Titular do Programa de Pós-Graduação em Educação da Unochapecó. Líder do PALAVRAÇÃO - Grupo de Estudos, Pesquisa e Documentação em Educação Ambiental Freiriana. E-mail: educador.ivo@unochapeco.edu.br
} 
construction of our word-world, as disciples of Freire who follow Its orientation not to follow it, but to reinvent it from our concrete historical reality.

Keywords: Paulo Freire, trilogy, praxis, dreams, utopia.

\section{PRIMEIRAS PALAVRAS...}

Há vinte anos o mundo perdia um de seus mais ilustres pensadores da educação do século XX: Paulo Freire. Partia dentre nós, mas deixava seu legado de luta e esperança (GADOTTI, 2001), centralmente focado ao ato pedagógico como fator de transformação social, criador de cidadania, desvelador do mundo opressor, enfim, Freire (2003) consolidou em sua obra e práxis a politicidade do ato educativo em defesa dos oprimidos, dos condenados da terra, dos esfarrapados do mundo.

Em seu livro-síntese, a Pedagogia do Oprimido, Freire (2003) nos mostrou muito mais que um novo jeito de educar, mas um processo em que educadores e educandos se colocam num movimento dialógico libertador de ambos ao problematizar os seus contextos de vida, seus espaços de vivência - o ato de alfabetização tornou-se uma epistemologia libertadora. Essa concepção de educação ficou mundialmente conhecida, colocando Paulo Freire como um dos maiores pensadores da educação, constituindo-se na principal reviravolta pedagógica do Século XX (NARODOWSKI, 1999), com experiências que começaram no nordeste brasileiro - no Centro de Cultura Dona Olegarinha até AngicosRN - e se expandiram, devido à violência da Ditadura Civil-Militar no Brasil nas décadas de 1960-1970 e o exílio de Freire, para várias partes do mundo, em especial, na América Latina e África, contribuindo decisivamente na constituição desses povos como protagonistas da sua própria história, tendo a educação e a alfabetização como uma ferramenta importante na luta pela libertação (FREIRE, 1978; 1986; ESCOBAR GUERRERO, 2010; BEISIEGEL, 1989; LYRA, 1996; FERNANDES; TERRA, 1994; ARAÚJO FREIRE, 2006).

Nesse texto, vamos conversar porque continuar lendo Freire depois de 20 anos de sua ausência entre nós e a 50 anos da primeira edição de seu emblemático livro Educação como prática da liberdade (FREIRE, 1986). Em resumo, vamos problematizar o mestre da problematização, saber quais os pontos da realidade da educação nacional atual que necessitam reflexão com bases freirianas e construir soluções e alternativas possíveis de enfrentamento a essas questões, numa tentativa de reinventar o legado de Paulo Freire. É preciso olhar com cuidado o tempo que estamos vivendo e o cenário político-pedagógico que está em curso, percebendo quais as forças estão tensionando a realidade, quais 
contradições estão colocando a história em movimento, quais os conflitos que nos cabe participar, intervir, transformar. Alerto aos leitores e leitoras: esse texto está profundamente conectado ao discurso político-pedagógico freiriano, portanto, é um texto comprometido com a mudança do mundo!

\section{CRISE DA DEMOCRACIA E ATAQUE A EDUCAÇÃO}

Mudar é difícil, mas é possivel. (Paulo Freire)

O Brasil viveu em 2016 (de maio a agosto) um duro golpe a democracia, um processo articulado entre instituições representativas públicas e a imprensa aberta (revistas e canais de televisão), deram fim às esperanças de sequência de financiamento público (FIES, PROUNI e o Ciências Sem Fronteiras) e de ampliação do sistema federal de ensino (universidades e institutos federais), com cortes de orçamento destas instituições educacionais e de pesquisa e do Ministério de Ciência, Tecnologia, Inovação e Comunicação (ESCOBAR, 2016; PAIVA, 2017) sob o argumento de que é necessário austeridade com os recursos públicos e que o governo deposto gastava mais do que arrecadava - o que na verdade demonstra o desinteresse pela educação e pesquisa científica de qualidade do atual governo e os partidos de sua base no Congresso, de centro, direita e extrema direita - que vem sistematicamente mostrando-se conservador e neoliberal.

O atual governo "ilegítimo e golpista", desde o começo, vem organizando ataques sistemáticos a Educação, além dos cortes de orçamento, estabeleceu ações que se colocam como verdadeiros retrocessos, sendo exemplo disso:

- A Reforma do Ensino Médio (MP-746), publicada sem diálogo com a sociedade, que atingirá todas as áreas da educação ao mudar diversos artigos da LDB, incluindo a aberração do "notório saber" como possibilidade de prática pedagógica, o que vai contra toda a política nacional de formação de educadores (BRASIL, 2015; DOURADO, 2015), e trazendo o Ensino Médio Técnico como alternativa para juventude (ao invés de fomentar o ingresso no Ensino Superior). 
- Fim do programa Brasil Alfabetizado em 28 de agosto de 2016, ato similar ao da Ditadura de 1964 quando encerrou as atividades do Plano Nacional de Alfabetização coordenado por Paulo Freire no MEC por considerar o Método Paulo Freire subversivo e com o objetivo de tornar o Brasil comunista (FREIRE; GUIMARÃES, 1987).

- Portaria Normativa ${ }^{\circ} 20$ do MEC, de 13 de outubro de 2016, às vésperas do dia do professor, que reduz o número de vagas nos cursos de graduação do Sistema Federal de Ensino, diminuindo as perspectivas que nossos jovens acessem o Ensino Superior (BRASIL, 2016).

- PEC 55, também conhecida como "PEC do fim do mundo", que congela os investimentos públicos nos próximos 20 anos (terrível coincidência com o tempo que durou a Ditadura Civil-Militar no Brasil), diminuindo consideravelmente os recursos para investimentos futuros em educação e saúde.

- Escola Sem Partido, também conhecido como "Lei da Mordaça", como padrão, supostamente, não-ideológico, postulando uma neutralidade impossível da educação e impondo uma postura passiva de educadores e educandos em sala de aula, focada num modelo conteudista e acrítica do ato pedagógico (FRIGOTTO, 2017; AÇÃO EDUCATIVA, 2016).

- Versão Final da BNCC, no dia 06 de abril de 2016 foi apresentada a terceira versão da Base Nacional Comum Curricular, que visa formular um currículo nacional comum a partir de dez competências, porém, a versão final suprimiu o Ensino Religioso e deixou de fora o Ensino Médio, embora a MP-746 tenha como referência a BNCC para a sua reformulação (BRASIL, 2017).

\section{O QUE DIRIA PAULO FREIRE}

A esperança é necessidade ontológica [...]

Não há mudança sem sonho Como não há sonho sem esperança. (Paulo Freire)

Frente a todas essas questões que dizem respeito diretamente a educação do nosso país, temos certeza que Paulo Freire estaria refletindo e dialogando com os educadores do Brasil para que fosse possível reverter os retrocessos e impedir que os projetos neoconservadores se efetivassem. Nessa direção, abaixo apresentamos as possíveis 
respostas baseadas em Freire a cada um desses problemas, tendo como referência as leituras de suas obras e a verificação de sua práxis, quando estava entre nós:

- A reforma do Ensino Médio via uma Medida Provisória demonstra que o atual governo não está disposto a dialogar com os educadores brasileiros, o que se caracteriza como uma postura autoritária, pois não consultou os principais interessados nessa mudança: educadores e educandos - tanto da escola básica como os do ensino superior. Além do mais, o foco do Ensino Médio Técnico desvirtua o interesse dos adolescentes e jovens, pois ao invés de motivá-los a fazer um curso superior, joga-os no mercado como se fosse esse o destino dos jovens brasileiros especialmente os filhos e filhas da classe trabalhadora - nem cogitando a questão da conciliação entre trabalho e estudo, o que já representaria um avanço. Outra questão que é relevante nesse cenário é que essa reforma se constitui num recorte de classe social muito específico, pois imagino que os jovens das classes A e B não serão motivados por seus pais a ir para o mercado depois do Ensino Médio, o que vai criar uma geração de filhos de trabalhadores encerrando a vida escolar no Ensino Médio (quando chegam até esse estágio da educação!), enquanto a geração dos filhos da classe A e B novamente serão instruídos ao comando, a liderança e a formação permanente, tendo como suporte para isso o ensino superior (FRIGOTTO, 2016).

- O fim do projeto de alfabetização de adultos está dentro da perspectiva ideológica de que não é importante aprender a ler e a escrever, já que esses adultos passaram a vida toda sem essa habilidade e não tiveram problemas em se inserir no mercado de trabalho. A questão é que não se aprende a ler para o mercado, mas para a vida, para ampliar a leitura do mundo e para escrever a própria história - faz parte de nosso processo de politização cotidiana e parte integrante da nossa cidadania plena e da formação humana integral. Encerrar processos de alfabetização mutila a história de vida dos adultos que, geralmente, por questões socioeconômicas desfavoráveis não se alfabetizaram na idade certa. Um país sério se envergonharia de ter milhões de analfabetos; no caso do nosso, esse processo está sendo estimulado pelo atual governo ou, no mínimo, negligenciado. Além do mais, o analfabetismo não é uma opção de alguns brasileiros, mas um problema histórico que ainda não foi resolvido, há uma malvadeza implícita na permanência desses sujeitos como analfabetos, desrespeitando o conhecimento do senso comum em seu 
caráter pedagógico e potencial dialógico-libertador (BENINCÁ, 2010; FREIRE, 2003; ARAÚJO FREIRE, 1989).

- Na contramão da história da educação dos últimos 15 anos, a redução do número de vagas no Ensino Superior enfraquece as condições de superação da pobreza, de transformação das histórias de vida de muitos jovens que vêm se preparando para entrar numa universidade ou instituto federal. Enquanto os governos anteriores vinham criando uma cultura de ampliação do número de anos de escolarização no nosso país, o atual governo ilegítimo ataca especificamente esse ponto fundamental que qualifica nossos cidadãos e cidadãs, para a criação de um país menos submisso e que mostra aos jovens a importância de ir para o mercado com mais preparo e com condição de salário muito melhor ou mais apto a empreender e tornar-se independente. Estudos demonstram que em média o acesso dos jovens ao Ensino Superior no Brasil cresceu, de 2000 a 2010, mais de $100 \%$ - sendo que chegou a mais de $200 \%$ na região norte, mais de $150 \%$ na região nordeste, $90 \%$ na região sudeste, quase $65 \%$ na região sul e $120 \%$ na região centro-oeste (CORBUCCI, 2014; PERICO; FINCO, 2017). Sigamos sonhamos e com esperança de um tempo em que o Ensino Superior seja obrigatório e desejado por todos os jovens do nosso país, não uma seleção para alguns privilegiados.

- A PEC 55 é um engodo, uma manipulação de informações que demonstra a falta de capacidade de gestão do Estado pelos nossos representantes políticos atuais e que se aproveitou da crise para ferir de morte a educação e a saúde pública, além dos demais serviços públicos. Mas que não deixou de ser benevolente com as grandes empresas, o capital estrangeiro (há anúncios de privatizações na União e nas Unidades da Federação das empresas públicas), renúncias fiscais em favor, perdão de dívidas, reformas da providência, terceirização do trabalho, entre outras ações que se coadunam com a PEC 55 num emaranhado malvado e desumano, que atingirá centralmente as classes C, D e E nos próximos 20 anos; a saúde perderá cerca de 645 bilhões de reais se o crescimento do país chegar a 2\% ao ano; haverá uma diminuição de cerca de 45 bilhões de reais em Educação até 2025 e vai inviabilizar a universalização do atendimento das crianças e adolescentes até 2020 como anunciado na meta do Plano Nacional de Educação, e o possível encerramento do Bolsa Família (PAIVA et al., 2016). 
- O movimento político de direita, Escola Sem Partido, é uma tentativa mesquinha de frear a consciência crítica de educadores e educandos, impedindo o diálogo aberto sobre questões político-pedagógicas, econômico-sociais, histórico-culturais que tangem o processo de ensinar e aprender na sala de aula (FRIGOTTO, 2017). Esse projeto se embasa em artigos da Constituição Federal de 1988, deturpando-os em favor de uma estratégia golpista retrógrada, transformando o processo de construção de conhecimento crítico-dialógico entre educandos e educadores numa simples transmissão de informação por parte do educador para os alunos cativos e silenciosos, como num regime militar - típico processo de "educação bancária" denunciado por Freire (2003) na década de 1960 -, não é por acaso que entre nós educadores estamos chamando esse movimento de "Lei da Mordaça". Na verdade, toda neutralidade proclamada é uma posição política escondida, como já nos ensinou Freire (2006), e esse projeto está exatamente nessa lógica. Além do mais, ensinar não é transferir conhecimento, mas criar as condições para sua criação e recriação, a partir do contexto concreto, e esse projeto de lei contraria esses princípios gnosiológico-epistemológio-político-ético-estético freirianos (FREIRE, 2004). Nesse sentido, o Escola Sem Partido é o movimento mais anti-freiriano da atualidade, com um interesse de classe burguesa explícito e uma malvadeza implícita ao tratar os educandos como passivos em sala de aula e os educadores como pessoas descomprometidas com o processo de ensino-aprendizagem para a formação da cidadania plena e crítica em vista da práxis transformadora das realidades de vivência em sua concretude (KOSIK, 2002; SÁNCHEZ VÁZQUEZ, 2011).

- Sobre a BNCC importa afirmar que ainda não está tranqüila essa última versão, carregada de limites, com cortes de conteúdo e ainda não apresentou as questões relativas ao Ensino Médio, que segundo a MP-746, seria a base da mudança. A contratação da Fundação Carlos Alberto Vanzolini - ligada a Escola Politécnica da $\mathrm{USP}^{3}$ - já sinaliza que o tecnicismo retornará com força na nova roupagem do

\footnotetext{
${ }^{3}$ Sem querer desmerecer a entidade selecionada, mas a título de esclarecimento, meu temor é o caráter essencialmente técnico da Fundação Vanzolini na área da Engenharia da Produção. Segundo seu próprio site, ela “[...] é uma instituição privada, sem fins lucrativos, criada, mantida e gerida pelos professores do Departamento de Engenharia de Produção da Escola Politécnica da Universidade de São Paulo (USP). A instituição tem como objetivo principal desenvolver e disseminar conhecimentos científicos e tecnológicos essenciais à Engenharia de Produção, à Administração Industrial, à Gestão de Operações e às demais atividades relacionadas que realiza com total caráter inovador. [...] é também um centro de referência internacional em temas de destaque para as empresas privadas e para entidades do setor público que buscam alcançar e manter padrões elevados de desempenho". Segundo essas informações, há certa carência de
} 
Ensino Médio brasileiro, aliás, é relevante falar que o contrato do Governo Federal para o serviço está orçado em mais de 18,9 milhões de reais para o período 20172019 para a consolidação, disponibilização, divulgação e discussão da terceira versão, mais de 787 mil reais por mês (sic!). ${ }^{4}$ Outros aspectos ainda precisam ser lembrados, tais como: o ensino de História passa a ser organizado por datas cronológicas dos fatos; o Ensino Religioso ficou de fora com o argumento da lei, de oferta obrigatória, mas matrícula facultativa, que será regulamentado pelos estados e municípios; o tema gênero não é trabalhado como conteúdo segundo os redatores, devido ao respeito à pluralidade - o que é uma pena, pois dependemos desses dois aspectos para ampliar a tolerância nas relações sociais.

\section{O QUE NÓS EDUCADORES PODEMOS FAZER}

Ensinar não é transferir conhecimento, Mas criar as possibilidades para a sua produção ou a sua construção. (Paulo Freire)

Mas não basta constatar todos estes problemas, reinventar o discurso de Freire como se ele estivesse aqui, se não visualizarmos ações concretas para efetivarmos a nossa práxis transformadora. Nessa direção, exponho aqui algo que venho repetindo nos lugares que tenho tido a oportunidade de discutir os problemas educacionais atuais.

Primeiro, temos que identificar qual é a nossa trincheira de luta, nosso lugar onde vamos fazer nossa intervenção transformadora. Eu, por exemplo, estou na pós-graduação em educação, participo de bancas de mestrado e doutorado, sou convidado - e obrigado - a publicar artigos em revistas científicas, tenho aulas na graduação e na pós-graduação; esse é o espaço que eu uso para fazer a luta contra três questões centrais que considero nossa batalha por uma educação de qualidade na atualidade brasileira, a saber:

1) o Brasil sofreu um golpe de estado jurídico-parlamentar em 2016 e precisamos lutar para restituir a democracia popular no nosso país, sob o risco de continuar sendo governados por políticos corruptos em conchavo com os donos do capital (leia-se grandes empresas nacionais e internacionais), aliás, os últimos acontecimentos vêm

expertise pedagógica para a construção da versão final nos próximos dois anos em diálogo com a diversidade de sujeitos desse processo na base da educação nacional. Disponível em: <http://vanzolini.org.br/institucional/quem-somos/> Acesso em: 22 maio 2017.

${ }^{4}$ Disponível em: <https://www.jusbrasil.com.br/diarios/140912365/dou-secao-3-23-03-2017-pg-23> Acesso: 22 maio 2017. 
afirmando essa prática corriqueira da classe política brasileira (de direita e de esquerda);

2) a reforma do Ensino Médio é um retrocesso conteudista e tecnicista, não resolve o problema do acesso ao mercado com qualidade e salário digno dos nossos jovens e constitui-se como uma "cortina de fumaça" contra o sonho de ingressar no ensino superior, além de desconsiderar a formação integral dos estudantes, converte a educação para a cidadania numa educação para o civismo, além de ter um nítido recorte de classe onde os mais pobres serão preteridos em relação aos mais abastados economicamente;

3) precisamos fazer a luta permanente contra a Lei da Mordaça que fere de morte a liberdade de produzir conhecimentos entre educadores e educandos tomado como ponto de partida o contexto de vivência, o entorno da escola, a vida comunitária, além de abrir precedentes para a punição dos educadores e tolher o direito constitucional de livre expressão das idéias e de profissão.

Você que lê esse texto agora, talvez encontre sua trincheira na escola pública, no sindicato da sua categoria, numa comunidade eclesial de base, no seu local de trabalho, o importante é estarmos sintonizados em lutarmos as mesmas lutas, pois esses projetos que vem afrontar a educação, na lógica neoconservadora e neoliberal precisam ser enfrentadas de forma organizada, articulada, mas também propositiva, mostrando aos que nos escutam/lêem, que outro país é possível, assumindo assim o nosso papel de liderança político-pedagógica na sintonia com a educação crítica postulada por Paulo Freire (DICKMANN; DICKMANN, 2016). Não podemos descansar nessa luta, porque todo dia somos pegos de surpresa com novos ataques à educação, precisamos estar vigilantes, ser criativos ao inventar novas formas de enfrentamento e resistência ativa, em resumo, temer jamais! Como afirmou o próprio Freire (2000), a mudança é difícil, mas é possível.

Muitos educadores já vêm construindo essa luta nas mais diversas áreas do conhecimento, numa verdadeira jornada que se constitui como uma pedagogia da reinvenção, tendo em vista que encontramos influências de Paulo Freire, 20 anos depois, na área da saúde pública com muito êxito a partir de círculos de cultura e da investigação temática (PRADO; SCHMIDT, 2016), na pedagogia latino-americana na relação com a Filosofia da Libertação (BOUFLEUER, 1991), no ensino da Filosofia na escola a partir da metodologia freiriana (FÁVERI, 2006), na área do ensino de Geografia (KAERCHER, 2007), na área do Direito e do pluralismo jurídico em diálogo com outros autores críticos (CAOVILLA, 2016), no cooperativismo habitacional autogestionário através dos círculos 
de cooperação (DICKMANN et al, 2011). Além disso, ainda, nas pesquisas e processos pedagógicos no Ensino Superior tendo como instrumento os círculos de cultura (SPIGOLON; CAMPOS, 2016), tomando os círculos de cultura como metodologia de pesquisa ou círculos epistemológicos (ROMÃO et al, 2006), fazendo auto(trans)formação de educadores a partir de Paulo Freire em grupos de pesquisa (HENZ; TONIOLO, 2015) e até formação de educadores ambientais na escola a partir do Método Paulo Freire e da pesquisa-ação (DICKMANN, 2015).

\section{CONSIDERAÕES FINAIS PROVISÓRIAS...}

Se nada ficar destas páginas, algo, pelo menos, Esperamos que permaneça: nossa confiança no povo. Nossa fé nos homens e na criação de um mundo em que seja menos difícil amar. (Paulo Freire)

Essa diversidade de experiências demonstra a atualidade do pensamento e da práxis de Paulo Freire, nos mostra que ele continua vivo, presente na prática político-pedagógica de educadores - tanto na educação formal, não-formal e informal -, ressignificando os processos, transformando as ações educativas em atos revolucionários, contribuindo assim para a construção de um outro mundo possivel.

Todas essas experiências constituem-se como um caleidoscópio políticopedagógico-histórico-cultural-ético-estético-epistemológico em que Paulo Freire é a referência e a lente para redimensionar e ampliar nossa leitura de mundo. É o processo pelo qual nossa palavração contribui para construir nossa palavramundo, sempre com Freire, como discípulos que seguem a sua orientação de não segui-lo, de reinventá-lo, de atualizar sua práxis a partir da nossa realidade histórica concreta.

Por fim, esperamos que Freire goste dessas homenagens nesse tempo que sentimos muito a sua falta 20 anos depois de sua partida (DICKMANN et al, 2017; SHIGUNOV NETO; FORTUNATO, 2017) que ele se sinta homenageado, pois vamos seguir lutando as suas lutas, reinventando seu legado.

Um forte abraço e força na luta!

\section{REFERÊNCIAS}

AÇÃO EDUCATIVA (Org.). A Ideologia do Movimento Escola Sem Partido: 20 autores desmontam o discurso. São Paulo: Ação Educativa, 2016. ARAÚJO FREIRE, Ana Maria. Analfabetismo no Brasil: da ideologia da interdição do corpo à ideologia nacionalista, ou de como deixar sem ler e escrever desde as Catarinas 
(Paraguaçu), Filipas, Madalenas, Anas, Genebras, Apolônias e Grácias até os Severinos, 1534-1930. Rio de Janeiro: Paz e Terra, 1989.

ARAÚJO FREIRE, Ana Maria. Paulo Freire: uma história de vida. Indaiatuba: Villa das Letras, 2006.

BEISIEGEL, Celso de Rui. Política e Educação Popular: a teoria e a prática de Paulo Freire no Brasil. São Paulo: Ática, 1989.

BENINCÁ, Elli. Educação: práxis e ressignificação pedagógica. Seleção e organização de Eldon Henrique Mühl. Passo Fundo: UPF, 2010.

BOUFLEUER, Pedro. Pedagogia latino-americana: Freire e Dussel. Ijuí: UNIJUÍ, 1991. (Coleção Educação; 12).

BRASIL. Conselho Nacional de Educação. Define as Diretrizes Curriculares Nacionais para a formação inicial em nível superior (cursos de licenciatura, cursos de formação pedagógica para graduados e cursos de segunda licenciatura) e para a formação continuada. Resolução CNE/CP n. 02/2015, de $1^{\circ}$ de julho de 2015. Brasília, Diário Oficial da República Federativa do Brasil, seção 1, n. 124, p. 8-12, 02 de julho de 2015. BRASIL. Ministério da Educação. Portaria Normativa no 20, de 13 de outubro de 2016. Dispõe sobre o procedimento de redução de vagas de cursos de graduação, ofertados por Instituições de Ensino Superior - IES integrantes do Sistema Federal de Ensino, e altera a Portaria Normativa $\mathrm{n}^{\circ}$ 10, de 6 de maio de 2016. Diário Oficial da República Federativa do Brasil, seção 1, n. 198, p. 12, 14 de outubro de 2016.

BRASIL. Ministério da Educação. Base Nacional Comum Curricular. Brasília: MEC, 2017.

CAOVILLA, Maria Aparecida Lucca. Descolonizar o direito na América Latina: o modelo do pluralismo e a cultura do bem-viver. Chapecó: Argos, 2016.

CORBUCCI, Paulo Roberto. Evolução do acesso de jovens à educação superior no Brasil. Brasília: IPEA, 2014. (Texto para discussão; 1950).

DICKMANN, Ivo. A formação de educadores ambientais: contribuições de Paulo Freire. 2015. Tese (Doutorado em Educação) - Programa de Pós-Graduação em Educação, Universidade Federal do Paraná, Curitiba. 2015.

DICKMANN, Ivo et al. Cooperativa de habitação e educação popular. Passo Fundo: Battistel; São Paulo: COOHABRAS, 2011.

DICKMANN, Ivo et al. (Orgs.). Pedagogia da Memória. Chapecó: Sinproeste, 2017. DICKMANN, Ivo. Paulo Freire Vive! 20 anos de memória e presença na práxis dos educadores. In: DICKMANN, Ivo et al. (Orgs.). Pedagogia da Memória. Chapecó: Sinproeste, 2017. p. 33-40.

DICKMANN, Ivanio; DICKMANN, Ivo. Pedagogia da Liderança. São Paulo: Dialogar, 2016.

DOURADO, Luiz Fernandes. Diretrizes curriculares nacionais para a formação inicial e continuada dos profissionais do magistério da educação básica: concepções e desafios. Educação e Sociedade, Campinas, v. 36, n. 131, p. 299-324, abr./jun. 2015. ESCOBAR, Herton. CNPQ corta 20\% das bolsas de iniciação científica no país. 2016. Disponível em: < http://ciencia.estadao.com.br/noticias/geral,cnpq-corta-20-das-bolsas-nopais, 10000067297> Acesso em: 22 maio 2017.

ESCOBAR GUERRERO, Miguel. Sonhos e utopias: ler Freire a partir da prática.

Brasília: Líber Livro, 2010.

FÁVERI, José Ernesto de. Filosofia da Educação: o ensino da Filosofia na perspectiva freireana. Petrópolis: Vozes, 2006.

FERNANDES, Calazans; TERRA, Antonia. 40 horas de esperança - o método Paulo Freire: política e pedagogia na experiência de Angicos. São Paulo: Ática, 1994. 
FREIRE, Paulo. Cartas à Guiné-Bissau: registros de uma experiência em processo. Rio de Janeiro: Paz e Terra, 1978. (O mundo hoje; 22).

FREIRE, Paulo. Educação como prática da liberdade. 17 ed. Rio de Janeiro: Paz e Terra, 1986.

FREIRE, Paulo. Pedagogia do oprimido. 37 ed. Rio de Janeiro: Paz e Terra, 2003.

FREIRE, Paulo. Pedagogia da autonomia. Rio de Janeiro: Paz e Terra; Anca/MST, 2004.

FREIRE, Paulo. Ação cultural para a liberdade e outros escritos. 11 ed. Rio de Janeiro:

Paz e Terra, 2006.

FREIRE, Paulo. Pedagogia da indignação: cartas pedagógicas e outros escritos. 8 reimp.

São Paulo: UNESP, 2008. (Coleção Prismas).

FREIRE, Paulo; GUIMARÃES, Sérgio. Aprendendo com a própria história I. Rio de

Janeiro: Paz e Terra, 1987. (Educação e Comunicação; 19).

FRIGOTTO, Gaudêncio. Entrevista. 2016. Disponível em:

<http://periodicos.fiocruz.br/pt-br/content/gaudencio-frigotto> Acesso em: 22 maio 2017.

FRIGOTTO, Gaudêncio (Org.). Escola "sem" partido: esfinge que ameaça a educação e a sociedade brasileira. Rio de Janeiro: LPP-UERJ, 2017.

GADOTTI, Moacir. Um legado de esperança. São Paulo: Cortez, 2001. (Coleção

Questões da nossa época; 91).

HENZ, Celso Ilgo; TONIOLO, Joze Medianeira Santos de Andrade (Orgs.). Dialogus: círculos dialógicos, humanização e auto(trans)formação de professores. São Leopoldo:

Oikos, 2015.

KAERCHER, Nestor André. Desafios e utopias no ensino de Geografia. 3 reimp. Santa Cruz do Sul: EDUNISC, 2007.

KOSIK, Karel. Dialética do concreto. Rio de Janeiro: Paz e Terra, 2002.

LYRA, Carlos. As quarenta horas de Angicos: uma experiência pioneira de educação.

São Paulo: Cortez, 1996.

NARODOWSKI, Mariano. Después de clase: desencantos y desafíos de la escuela actual.

Buenos Aires: Novedades Educativas, 1999. (Colección Edu/causa).

PAIVA, Andrea Barreto et al. O novo regime fiscal e suas implicações para a política de assistência social no Brasil. Brasília: IPEA, 2016. (Nota Técnica; 27).

PAIVA, Thais. Cortes ameaçam pesquisa científica no Brasil. Disponível em:

$<$ http://www.cartaeducacao.com.br/reportagens/cortes-ameacam-pesquisa-cientifica-nobrasil/> Acesso em: 10 jan. 2017.

PERICO, Alessandra Vanessa Klein; FINCO, Andrei. O direito ao acesso gratuito ao ensino superior no Brasil como garantia do direito fundamental social à educação. In:

DICKMANN, Ivo et al. (Orgs.). Pedagogia da Memória. Chapecó: Sinproeste, 2017. p. 117-136.

PRADO, Marta Lenise; SCHMIDT, Kenia Reibnitz (Orgs.). Paulo Freire: a boniteza de ensinar e aprender na saúde. Florianópolis: NFR/UFSC, 2016.

ROMÃO, José Eustáquio et al. Círculo epistemológico: círculo de cultura como metodologia de pesquisa. Educação e Linguagem, São Bernardo do Campo, Ano 9, n. 13, p. 173-195, jan./jun., 2006.

SÁNCHEZ VÁZQUEZ, Adolfo. Filosofia da práxis. 2 ed. Buenos Aires: CLACSO; São Paulo: Expressão Popular, 2011.

SHIGUNOV NETO, Alexandre; FORTUNATO, Ivan (Orgs.). 20 anos sem Paulo Freire: trajetórias de sua pedagogia libertária. São Paulo: Edições Hipótese, 2017.

SPIGOLON, Nima Imaculada; CAMPOS, Camila Brasil Gonçalves (Orgs.). Círculos de cultura: teoria, prática e práxis. Curitiba: CRV, 2016.

Submetido em: 20-05-2017. Publicado em: 01-06-2017.

Rev. Eletrônica Mestr. Educ. Ambient. E-ISSN 1517-1256, Edição especial XIX Fórum de Estudos: Leituras de Paulo Freire, p. 79-90, junho, 2017. 